\title{
Sensitivity of polar stratospheric ozone loss to uncertainties in chemical reaction kinetics
}

\author{
S. R. Kawa ${ }^{1}$, R. S. Stolarski ${ }^{1}$, P. A. Newman ${ }^{1}$, A. R. Douglass ${ }^{1}$, M. Rex ${ }^{2}$, D. J. Hofmann ${ }^{3}$, M. L. Santee ${ }^{4}$, and \\ K. Frieler ${ }^{2, *}$ \\ ${ }^{1}$ NASA Goddard Space Flight Center, Greenbelt, MD, USA \\ ${ }^{2}$ Alfred Wegener Institute for Polar and Marine Research, Potsdam, Germany \\ ${ }^{3}$ National Oceanic and Atmospheric Administration, Earth Systems Research Laboratory, Boulder, CO, USA \\ ${ }^{4}$ Jet Propulsion Laboratory, California Institute of Technology, Pasadena, CA, USA \\ * now at: Potsdam Institute for Climate Impact Research (PIK), Potsdam, Germany
}

Received: 19 May 2009 - Published in Atmos. Chem. Phys. Discuss.: 17 June 2009

Revised: 9 September 2009 - Accepted: 6 October 2009 - Published: 16 November 2009

\begin{abstract}
The impact and significance of uncertainties in model calculations of stratospheric ozone loss resulting from known uncertainty in chemical kinetics parameters is evaluated in trajectory chemistry simulations for the Antarctic and Arctic polar vortices. The uncertainty in modeled ozone loss is derived from Monte Carlo scenario simulations varying the kinetic (reaction and photolysis rate) parameters within their estimated uncertainty bounds. Simulations of a typical winter/spring Antarctic vortex scenario and Match scenarios in the Arctic produce large uncertainty in ozone loss rates and integrated seasonal loss. The simulations clearly indicate that the dominant source of model uncertainty in polar ozone loss is uncertainty in the $\mathrm{Cl}_{2} \mathrm{O}_{2}$ photolysis reaction, which arises from uncertainty in laboratory-measured molecular cross sections at atmospherically important wavelengths. This estimated uncertainty in $J_{\mathrm{Cl}_{2} \mathrm{O}_{2}}$ from laboratory measurements seriously hinders our ability to model polar ozone loss within useful quantitative error limits. Atmospheric observations, however, suggest that the $\mathrm{Cl}_{2} \mathrm{O}_{2}$ photolysis uncertainty may be less than that derived from the lab data. Comparisons to Match, South Pole ozonesonde, and Aura Microwave Limb Sounder (MLS) data all show that the nominal recommended rate simulations agree with data within uncertainties when the $\mathrm{Cl}_{2} \mathrm{O}_{2}$ photolysis error is reduced by a factor of two, in line with previous in situ $\mathrm{ClO}_{\mathrm{x}}$ measurements. Comparisons to simulations using recent cross sections from Pope et al. (2007) are outside the constrained error bounds
\end{abstract}

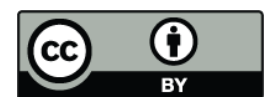

Correspondence to: S. R. Kawa (stephan.r.kawa@nasa.gov) in each case. Other reactions producing significant sensitivity in polar ozone loss include $\mathrm{BrO}+\mathrm{ClO}$ and its branching ratios. These uncertainties challenge our confidence in modeling polar ozone depletion and projecting future changes in response to changing halogen emissions and climate. Further laboratory, theoretical, and possibly atmospheric studies are needed.

\section{Introduction}

The annual loss of ozone $\left(\mathrm{O}_{3}\right)$ in the springtime polar lower stratosphere of both hemispheres is a key diagnostic for ozone assessment, recovery prediction, and chemistry interaction with climate change. To a large extent, our confidence in understanding and projecting changes in polar (and global) $\mathrm{O}_{3}$ is based on our ability to simulate these loss processes in numerical models of chemistry and transport. The fidelity of the models is assessed in comparison with a wide range of observations. The models depend on laboratory-measured kinetic reaction rates and photolysis cross sections to simulate molecular interactions (Sander et al. (2006), hereafter referred to as JPL06). The rates of all of these reactions are subject to uncertainty, some of which is substantial. Given the complexity of the models, however, it is difficult to quantify uncertainty in many aspects of the system.

In this study we use trajectory box-model simulations for Antarctic and Arctic stratospheric $\mathrm{O}_{3}$ to quantify the uncertainty in loss attributable to known reaction kinetic uncertainties. Following the method of earlier work, rates and uncertainties from the latest laboratory evaluation are applied in

Published by Copernicus Publications on behalf of the European Geosciences Union. 
random combinations (Stolarski et al., 1978; Stolarski and Douglass, 1986; Fish and Burton, 1997; Considine et al., 1999). We compare the results with observations to evaluate which combinations are consistent with atmospheric data. This also allows us to identify the key reactions and rates contributing the largest potential errors as a guide for future work. Note that these simulations only test rate uncertainties, and their fidelity depends on the accuracy and completeness of the underlying chemical reaction set. Transport uncertainty is not included; however, the scenarios are chosen to minimize sensitivity to transport errors (see Antarctic trajectory discussion and references on Match trajectory uncertainties below).

The work is motivated by several recent observational and laboratory studies of processes involved in polar stratospheric $\mathrm{O}_{3}$ loss that have prompted a reexamination of aspects of our understanding for this key indicator of global change (Pope et al., 2007; von Hobe et al., 2007; Schofield et al., 2008). In particular, the rate of polar $\mathrm{O}_{3}$ loss is predominantly controlled by catalytic halogen reactions:

$\mathrm{ClO}+\mathrm{ClO}+\mathrm{M} \rightleftarrows \mathrm{Cl}_{2} \mathrm{O}_{2}+\mathrm{M}$

$\mathrm{Cl}_{2} \mathrm{O}_{2}+h v \rightarrow 2 \mathrm{Cl}+\mathrm{O}_{2}$

and

$\mathrm{ClO}+\mathrm{BrO} \rightarrow \mathrm{BrCl}+\mathrm{O}_{2}$

$$
\mathrm{Br}+\mathrm{ClOO}
$$

$\mathrm{Br}+\mathrm{OClO}$

$\mathrm{BrCl}+h v \rightarrow \mathrm{Br}+\mathrm{Cl}$

followed by

$\mathrm{Cl}+\mathrm{O}_{3} \rightarrow \mathrm{ClO}+\mathrm{O}_{2}$

$\mathrm{Br}+\mathrm{O}_{3} \rightarrow \mathrm{BrO}+\mathrm{O}_{2}$

Laboratory measurements of the $\mathrm{Cl}_{2} \mathrm{O}_{2}$ photolysis cross sections by Pope et al. (2007) imply a much slower rate of photolysis than indicated by previous measurements (Sander et al. (2006) and references within). This slower photolysis has a major impact in reducing the calculated $\mathrm{O}_{3}$ loss rate in polar conditions. More recent lab studies by von Hobe et al. (2009) and Chen et al. (2009) infer that Pope et al. over-corrected for impurities leading to an underestimate in the $\mathrm{Cl}_{2} \mathrm{O}_{2}$ cross sections. Even these most recent measurements, however, disagree by more than a factor of 2 at critical wavelengths and lie on opposite sides of the JPL06 recommendation. In addition there is significant uncertainty in the forward and reverse rates of the $\mathrm{ClO} / \mathrm{Cl}_{2} \mathrm{O}_{2}$ equilibrium reaction (R1) and their temperature dependence (von Hobe et al., 2007). Note that throughout this paper $\mathrm{Cl}_{2} \mathrm{O}_{2}$ refers to the symmetric isomer of the $\mathrm{ClO}$-dimer $(\mathrm{ClOOCl})$.
The addition of $\mathrm{Br}$ in the stratosphere from short-lived bromocarbons (Salawitch et al., 2005), not generally included in global chemistry-transport models (CTMs), increases the importance of Reaction (R3) and its branching ratios $(\mathrm{a}-\mathrm{c})$. Assessment of polar $\mathrm{O}_{3}$ loss rates in Frieler et al. (2006) and WMO (2007) found that models generally required both additional stratospheric $\mathrm{Br}$ and a faster rate of $\mathrm{Cl}_{2} \mathrm{O}_{2}$ photolysis than current recommendations to match observations.

In this paper we attempt to assess the impact of these uncertainties in simulating polar $\mathrm{O}_{3}$ loss against the backdrop of known uncertainties in kinetic rates using a quantitative model for the overall chemical error limits. Our overall objective is to evaluate the consistency of our theoretical understanding, model chemical mechanism, and kinetic rate parameters, including known kinetic uncertainties, with recent observations of Arctic and Antarctic winter/spring $\mathrm{O}_{3}$ loss. Specifically, we 1) revisit the impact of kinetic uncertainties in models using JPL06 evaluations as well as new lab results (i.e., Pope et al., 2007), 2) assess the impact of constraints on photolysis uncertainty limits provided by atmospheric observations, and 3) identify the major uncertainty sources in simulating polar $\mathrm{O}_{3}$ loss that result from uncertainties in kinetics as a potential guide to further lab measurements.

In the next section we outline the trajectory chemistry scenarios and Monte Carlo method used for calculating uncertainty bounds from the kinetic data. We also describe selection of data for comparison with the models. We then present the statistics of the calculations using JPL06 and the impact of constraining $\mathrm{Cl}_{2} \mathrm{O}_{2}$ photolysis error limits using atmospheric data. Following that we present comparisons with observations and implications for understanding processes and rates. We find that comparisons with ozonesonde and Aura Microwave Limb Sounder (MLS) data in the Antarctic and Match observations in the Arctic present a consistent picture of seasonal $\mathrm{O}_{3}$ loss and chlorine partitioning vis-àvis the kinetic rates and their uncertainties. The penultimate section summarizes key rate uncertainties in the polar $\mathrm{O}_{3}$ loss reaction system with potential for future measurement work, and the final section provides summary remarks.

\section{Model scenarios and diagnostic observations}

Results are presented below for the Antarctic and Arctic using slightly different calculation procedures and somewhat different observational data. The methods were developed independently but the findings are consistent between them, and both methods are described here. Our baseline for kinetic rates and uncertainties is JPL06 but in some cases reference is made to earlier studies using JPL02 (Sander et al., 2003), JPL97 (DeMore et al., 1997), and JPL94 (DeMore et al., 1994). Note that the recommendation for $\mathrm{Cl}_{2} \mathrm{O}_{2}$ photolysis cross sections and uncertainties has not changed since JPL97. 


\subsection{Antarctic model}

A single, representative trajectory parcel was chosen for the Antarctic vortex from 29 July to 27 October. This parcel was selected from a run of 360 trajectory samples initialized at $80^{\circ} \mathrm{S}$ at $1^{\circ}$ longitude increments on 27 September 2000 (a typical stratospheric winter). The trajectories were run backward 60 days to 29 July and then forward 30 days to 27 October. The trajectory winds were from the United Kingdom Meteorological Office operational analysis. The parcel was selected to be deep in the vortex at the time of maximum ozone loss, and have near-median potential temperature evolution and latitude-longitude excursions. In general, the vortex parcels follow statistically similar paths through this time period. This representative parcel's average latitude was $73^{\circ} \mathrm{S}$ varying between $89^{\circ} \mathrm{S}$ and $57^{\circ} \mathrm{S}$ at pressures from 40 to $67 \mathrm{hPa}$, and it diabatically descended over the course of the trajectory.

Chemical evolution along the trajectory was calculated using the standard Goddard stratospheric mechanism (Kawa et al., 1997), which is typical of current models. The initial chemical state of the trajectory was taken from a run of the global CTM with minor adjustments to the $\mathrm{O}_{3}$ and reactive chlorine $\left(\mathrm{Cl}_{\mathrm{y}}\right)$ abundances to more closely correspond to MLS measurements. The initialization on July 29 presents a fully activated partitioning of $\mathrm{Cl}_{\mathrm{y}}$. Polar stratospheric clouds (PSCs) form intermittently during the first half of the trajectory when the temperature is sufficiently low. An additional 5 pptv of $\mathrm{Br}_{\mathrm{y}}$ was included in the standard runs to represent the contribution from short-lived bromine-containing compounds reaching the stratosphere (WMO, 2007). Overhead $\mathrm{O}_{3}$ and surface albedo for the photolysis calculations were derived from TOMS observations for the year 2000 interpolated to the trajectory (Pierson et al., 2000). The time series of $\mathrm{O}_{3}$ along the trajectory for standard JPL06 chemistry can be seen in the central red curve in Fig. 1.

\subsection{Kinetics uncertainties and Monte Carlo simulations}

Kinetics uncertainties for the Antarctic calculations in this paper were taken from JPL06. Since all reaction rates must be positive, a lognormal distribution was assumed for the uncertainty in each rate coefficient, as described by Stolarski et al. (1978). That is, the nominal (median) value is multiplied and divided by a factor scaled to the JPL06 uncertainty estimates assuming a normal distribution of errors. The uncertainties in JPL06 are expressed as uncertainty in the measurement at a temperature of $298 \mathrm{~K}$ and an independent uncertainty in the temperature dependence. We convert these to uncertainties in the coefficients of the Arrhenius form of the reaction rate coefficient:

$k(T)=A \exp (-E / R / T)$

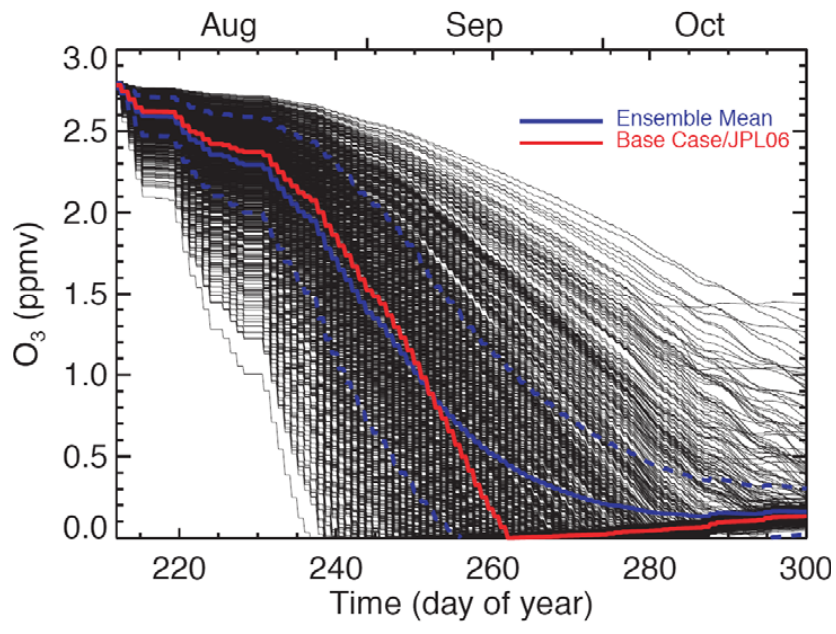

Fig. 1. Calculated $\mathrm{O}_{3}$ as a function of time along the trajectory for simulations using each of the 1000 Monte Carlo reaction rate sets. The base case using nominal JPL06 rate recommendations is shown by the red curve. The solid and dashed blue lines are the mean and mean \pm standard deviation of $\mathrm{O}_{3}$ from the 1000 cases at each time. This scenario uses the JPL06 recommended factor of 3 uncertainty on $\mathrm{Cl}_{2} \mathrm{O}_{2}$ photolysis at wavelengths $>300 \mathrm{~nm}$ as discussed in the text.

by the method described in JPL06. For uncertainties in termolecular reactions we have used the low-pressure limit form

$k(T)=A T^{-n}$

and the estimates for uncertainty in k298 and temperature dependence as described in JPL06. The rate coefficients use the full formula given in JPL06, but the uncertainties were calculated using only the low-pressure limit. Uncertainties in photolysis coefficients were also taken from JPL06 and were applied uniformly at all wavelengths. The exception to this is the photolysis rate for $\mathrm{Cl}_{2} \mathrm{O}_{2}$, for which somewhat different assumptions were made as described later in this section.

To evaluate the collective importance of the uncertainties in the 120 reactions and 37 photolysis $(J)$ coefficients, we use a Monte Carlo technique previously described by Stolarski et al. (1978), Stolarski and Douglass (1986), and Considine et al. (1999). Briefly, a set of random rate coefficients and $J$ coefficients, constrained to the recommended uncertainties, is produced for each simulation. This is repeated 1000 times to produce a distribution of constituent concentrations along the selected trajectory.

The sensitivity to uncertainties in the heterogeneous reactions was tested in separate runs (discussed in Sect. 3), but was not included in the Monte Carlo runs because of the different formalism required for these reactions. We feel justified in this simplification because of the low sensitivity to heterogeneous rates for this case.

The $\mathrm{Cl}_{2} \mathrm{O}_{2}$ cross section presents a special case for this paper. The rate evaluation panels attempt to estimate statistical 
uncertainties on the photolysis rates based on expert knowledge and consensus regarding reported results (JPL06). For $\mathrm{Cl}_{2} \mathrm{O}_{2}$ cross sections, the lab measurements are very difficult, results vary widely, and the number of measurements is small (5 at stratospherically important wavelengths and temperatures), so the uncertainty estimate is correspondingly large (JPL06). We carried out 3 sets of Monte Carlo simulations (1000 members to each set). The first of these used the uncertainty stated in JPL06 (we used the uncertainty for the long wavelength portion of the spectrum, $>300 \mathrm{~nm}$ ). The second halved the uncertainty factor ( 3 to 1.5 ) to account for the constraints provided by atmospheric measurements as discussed below. The third used the recent Pope et al. (2007) cross sections as a baseline and the reduced uncertainty bounds.

As a further test, we evaluated the sensitivity of the $\mathrm{O}_{3}$ loss along the selected trajectory to each of the rate coefficients by varying that coefficient individually by plus and minus one sigma.

\subsection{Antarctic observations}

The modeled evolution of $\mathrm{O}_{3}$ is compared to ozonesondes at South Pole station (Hofmann et al., 1997) and McMurdo station (Nardi et al., 1999), and satellite data from Aura MLS (Santee et al., 2008). HCl from MLS is also compared to the model. For the sonde data at each site, we first interpolate the $\mathrm{O}_{3}$ profile to $50 \mathrm{hPa}$ and then average data on each day of the year from 1998 to 2007 excluding 2002 (because of the September major warming). For MLS, we interpolate potential temperature/equivalent latitude averaged daily data for 2005-2007 to the potential temperature/equivalent latitude of the sample trajectory selected above. The 3-year average and range of yearly-interpolated data are shown below. Similar results are obtained using zonal mean MLS at $76^{\circ} \mathrm{S}$ to $80^{\circ} \mathrm{S}$ between 46 and $68 \mathrm{hPa}$; the potential temperature/equivalent latitude averaging provides a convenient method to aggregate the data. Antarctic $\mathrm{O}_{3}$ loss is fairly consistent from year to year in the late 1990s and 2000s except for 2002 and 2004, which had anomalously warm conditions (Hoppel et al., 2005; Santee et al., 2008). In each year, observed $\mathrm{O}_{3}$ mixing ratios in the polar lower stratospheric vortex approach zero by mid-to-late September.

\subsection{Arctic Match observations and model}

For the Arctic, we concentrate on the polar winter of 1999-2000 because of the extensive in situ and remote measurement sets available during that year, including the SOLVE/THESEO and Match field campaigns (Newman et al., 2002; Rex et al. 2002). Polar $\mathrm{O}_{3}$ loss is derived from regression analysis of sequential Match ozonesonde observations along air parcel trajectories (Rex et al., 1998, 2003). A photochemical box model is run along the identical trajectories used for the $\mathrm{O}_{3}$ loss calculations. The chemical model uses a simplified mechanism that includes known reactions

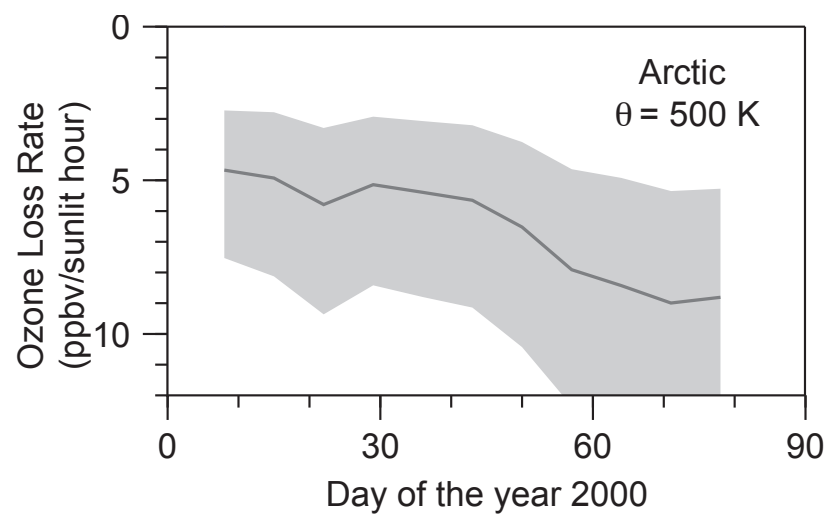

Fig. 2. Calculated $\mathrm{O}_{3}$ loss rates as a function of time along the ensemble of Match trajectories at a potential temperature of $500 \mathrm{~K}$ varying the kinetic rates within JPL02 uncertainty limits and assuming complete activation of $\mathrm{Cl}_{\mathrm{y}}$. The median case for JPL02 $\pm 34 \%$ of the distribution of reaction rate sets is shown (uncertainty interval of a lognormal distribution).

relevant to $\mathrm{O}_{3}$ loss in the lower stratosphere, with $\mathrm{Cl}_{\mathrm{y}}$ and $\mathrm{Br}_{\mathrm{y}}$ constrained by observations (Rex et al., 2003; Frieler et al., 2006). The $\mathrm{Br}_{\mathrm{y}}$ abundance is based on DOAS profile measurements over Sweden in 2000, reflecting a contribution of approximately $6 \mathrm{pptv}$ from short-lived bromocarbons beyond that from a standard model (Frieler et al., 2006). In a method similar to that for the Antarctic, chemical model runs were done along the Match trajectories randomly varying the rates of the Match chemical mechanism according to the distribution of uncertainties given by JPL02.

\section{Monte Carlo simulation results}

The full 1000-member ensemble of calculated $\mathrm{O}_{3}$ time series for the Antarctic is shown in Fig. 1 based on rate uncertainties as tabulated in JPL06. A wide range in possible $\mathrm{O}_{3}$ loss is found, from complete destruction before the end of $\mathrm{Au}-$ gust (day 238) to less than 50\% loss by the end of October (day 304). This range is driven almost entirely by the stated uncertainty in $\mathrm{Cl}_{2} \mathrm{O}_{2}$ photolysis, which is a factor of three at wavelengths greater than $300 \mathrm{~nm}$ based on uncertainty in the measured molecular cross sections (JPL06). Almost all calculated lower stratospheric photolysis of $\mathrm{Cl}_{2} \mathrm{O}_{2}$ takes place at the longer wavelengths, where the laboratory measurements are most susceptible to possible contamination from photolysis of other chlorine species (Burkholder et al., 1990; Huder and DeMore, 1995; Pope et al., 2007). Based on JPL06 uncertainties (i.e., even without considering the results of Pope et al., 2007), modeled $\mathrm{O}_{3}$ loss rates have an uncertainty of up to a factor of three. The same conclusion is reached for analysis of $\mathrm{O}_{3}$ loss in the Arctic using Match trajectory-chemistry (Fig. 2). The upper and lower limits of the uncertainty interval (i.e., the inner $68 \%$ of the calculated ozone loss rates) 
differ by a factor of three. The primary message of this paper is that the stated uncertainty in the photolysis rate $J_{\mathrm{Cl}_{2} \mathrm{O}_{2}}$ from laboratory measurements precludes modeling of polar $\mathrm{O}_{3}$ loss within any useful quantitative error limits, and, at this level of uncertainty, not much else matters. The loss rate uncertainties from $J_{\mathrm{Cl}_{2} \mathrm{O}_{2}}$ are larger than any produced by varying other photolysis rates, $\mathrm{Br}_{\mathrm{y}}$, other tracers, reaction rates, trajectories, or transport within reasonable limits.

In order to move beyond the impact of nominal uncertainty in $J_{\mathrm{Cl}_{2} \mathrm{O}_{2}}$ to see what other rates and factors most strongly affect polar $\mathrm{O}_{3}$ loss, we constrained the uncertainty in $J_{\mathrm{Cl}_{2} \mathrm{O}_{2}}$ based on analysis of in situ atmospheric measurements of $\mathrm{ClO}$ and $\mathrm{Cl}_{2} \mathrm{O}_{2}$ (Stimpfle et al., 2004). Comparing the measured $\mathrm{ClO} / \mathrm{Cl}_{2} \mathrm{O}_{2}$ with model formulations for this ratio as a function of solar zenith angle, Stimpfle et al. (2004) found that values of $J_{\mathrm{Cl}_{2} \mathrm{O}_{2}}$ within about $50 \%$ of JPL02 are consistent with observations within the uncertainty of the measurements and the $\mathrm{ClO} / \mathrm{Cl}_{2} \mathrm{O}_{2}$ equilibrium Reaction (R1). von Hobe et al. (2008) reached a very similar range of uncertainty for $J_{\mathrm{Cl}_{2} \mathrm{O}_{2}}$ based on an extensive analysis of observations and lab measurements, including uncertainties in the $\mathrm{ClO} / \mathrm{Cl}_{2} \mathrm{O}_{2}$ equilibrium reactions. The analysis of in situ $\mathrm{ClO}$ measurements from Avallone and Toohey (2001) are also within this range. Therefore, we repeated our Monte Carlo uncertainty calculations using a halved uncertainty factor of 1.5 for $J_{\mathrm{Cl}_{2} \mathrm{O}_{2}}$ (which is the nominal uncertainty for photolysis at wavelengths less than $300 \mathrm{~nm}$ from JPL06), consistent with the results from atmospheric $\mathrm{ClO}$ and $\mathrm{Cl}_{2} \mathrm{O}_{2}$ measurements.

The results of the Antarctic trajectory scenario using $J_{\mathrm{Cl}_{2} \mathrm{O}_{2}}=J_{\mathrm{Cl}_{2} \mathrm{O}_{2}}(1 \pm \sigma), \sigma=0.5$, are shown in Fig. 3 (red line on the left side with darker grey shading). The uncertainty in the range of $\mathrm{O}_{3}$ losses is still large. Using the date at which the $\mathrm{O}_{3}$ mixing ratio first reaches a value less than $0.1 \mathrm{ppmv}$, the values range around a base value of day 260.9 (16 September) from day 251 (7 September) to day 276 (2 October) for the JPL06 case at the 95\% confidence limits. Uncertainty in $\mathrm{Cl}_{2} \mathrm{O}_{2}$ photolysis is still the largest source of uncertainty in the $\mathrm{O}_{3}$ loss (more below), but at this uncertainty level other error sources are discernable. For example, the scenarios using Pope et al. (2007) cross sections for the baseline are distinguishable from JPL06 at or near the 95\% confidence level (Fig. 3a). The minimum $\mathrm{O}_{3}$ in the base Pope et al. case reaches a minimum of $0.09 \mathrm{ppmv}$ on day 294. The statistics of the distribution of $\mathrm{O}_{3}$ on day 250 in the different scenarios is seen in Fig. 3b. There is little overlap between the JPL06 and Pope et al. (2007) photolysis distributions and both are slightly skewed toward low $\mathrm{O}_{3}$ mixing ratios. In each, the base case, mean, and most probable value are within $0.1 \mathrm{ppmv}$ of each other. The impact of uncertainty in other kinetic rates is discussed in Sect. 4 below.

In the course of developing these scenarios, we have tested a number of other sensitivities in polar $\mathrm{O}_{3}$ loss that are worth comparing to the kinetics uncertainty range shown here. The $\mathrm{O}_{3}$ loss rates are sensitive to the amounts of $\mathrm{Cl}_{\mathrm{y}}$ and $\mathrm{Br}_{\mathrm{y}}$ as
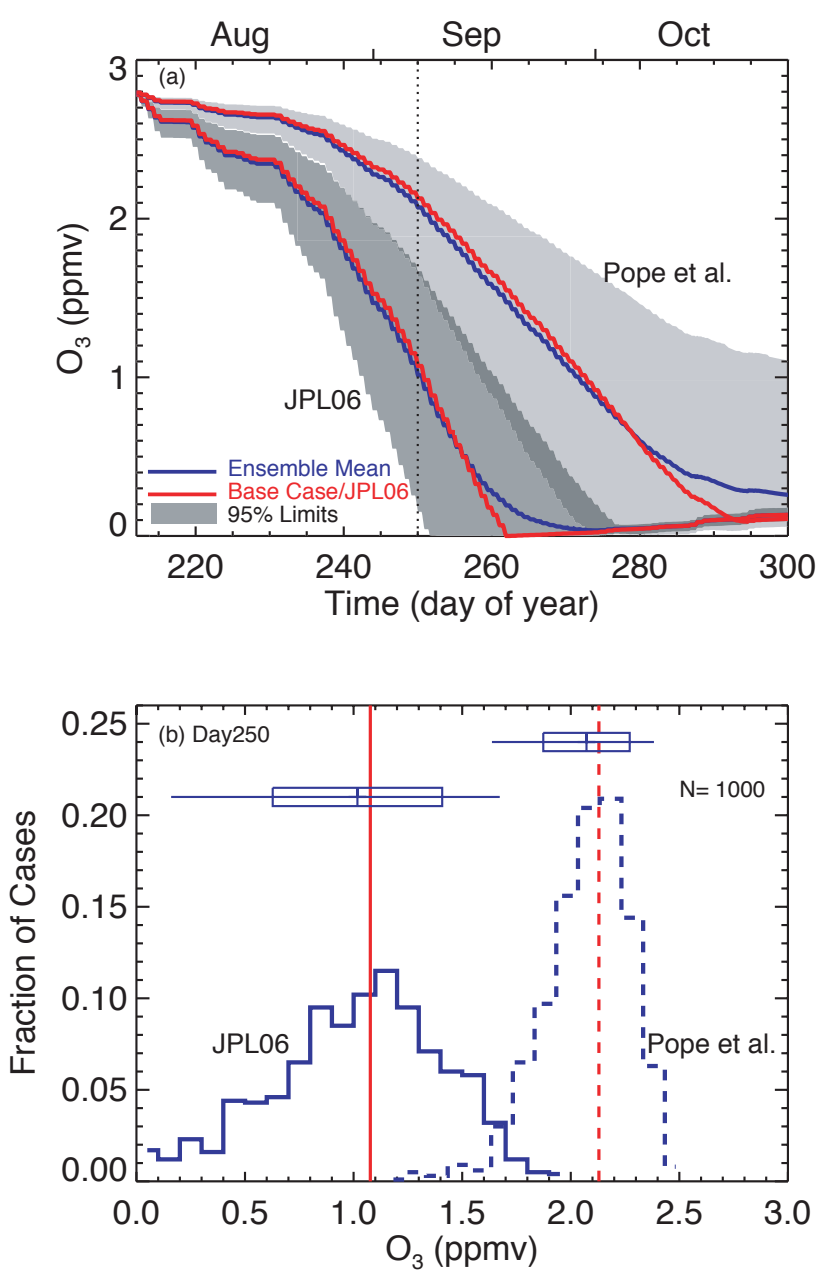

Fig. 3. $\mathrm{O}_{3}$ loss calculations with uncertainty in $J_{\mathrm{Cl}_{2} \mathrm{O}_{2}}$ constrained to a factor of 1.5. (a) Gray shaded areas encompass the median $95 \%$ of $\mathrm{O}_{3}$ mixing ratio values from the scenario distribution on each day for the JPL06 and Pope et al. (2007) cases. Red lines are the calculations using the nominal rates from JPL06 and JPL06 with Pope et al. (2007) cross sections substituted for $J_{\mathrm{Cl}_{2} \mathrm{O}_{2}}$. Solid blues lines in (a) are mean $\mathrm{O}_{3}$. (b) Probability distributions of $\mathrm{O}_{3}$ on day 250 from the Monte Carlo set of kinetic rates using JPL06 (solid) and JPL06 and Pope et al. (2007) (dashed). Box and whisker forms show mean, \pm 1 standard deviation, and $95 \%$ limits of the $\mathrm{O}_{3}$ values.

expected. Reducing $\mathrm{Br}_{\mathrm{y}}$ by 5 pptv (i.e., not adding $\mathrm{Br}$ from short-lived halocarbons) and $8 \mathrm{pptv}$ from nominal (21 pptv) results in increasing the date of $\mathrm{O}_{3}<0.1 \mathrm{ppmv}$ by 2.5 and 4.2 days, respectively, beyond the base case. Decreasing $\mathrm{Cl}_{\mathrm{y}}$ by $15 \%$ (approximately the difference going from 2000 to 1992 in the lower stratospheric vortex) extends the date of $\mathrm{O}_{3}<0.1$ ppmv by 4 days. Note that $\mathrm{Cl}_{\mathrm{y}}$ decreases by about $3 \%$ between 2000 and 2006 (Newman et al., 2006).

The $\mathrm{O}_{3}$ loss is nearly insensitive to the rates of heterogeneous processes in the Antarctic scenario. $\mathrm{Cl}_{\mathrm{y}}$ is nearly fully processed to reactive forms on 1 August and little recovery 
to reservoir species, $\mathrm{HCl}$ and $\mathrm{ClONO}_{2}$, occurs in the low sun conditions through September. Varying the heterogeneous reaction rates by a factor of 2 changes the time of $\mathrm{O}_{3}<0.1 \mathrm{ppmv}$ by less than an hour. Heterogeneous reactions on liquid ternary solution droplets and the occasional PSCs are more than fast enough to keep all $\mathrm{Cl}_{\mathrm{y}}$ activated until the final shift to $\mathrm{HCl}$ that occurs when $\mathrm{O}_{3}$ is depleted (see below). The loss rates are sensitive to temperature with the date of $\mathrm{O}_{3}<0.1$ shifting by -1.7 to 2.3 days for a constant delta temperature of -5 and $5 \mathrm{~K}$, respectively. Changes in the assumed surface albedo ( 0.1 to 0.6$)$ have only a negligible effect $(<0.5 \mathrm{~d})$ for the photolysis calculations in this scenario, while varying overhead $\mathrm{O}_{3}( \pm 50 \mathrm{DU})$ changes the date by \pm 1 day.

The shape of the $\mathrm{O}_{3}$ loss curve and date of mixing ratio $<0.1$ does depend strongly on the parcel trajectory through the Antarctic vortex. We have run thousands of trajectories from different initial conditions in the Antarctic over the time of our selected parcel to examine this sensitivity. A wide range of $\mathrm{O}_{3}$ values is possible (although not as wide as in Fig. 1). The probability distribution function for day 250 (not shown) is relatively flat and the distribution of $\mathrm{O}_{3}$ across the various trajectories is decidedly not Gaussian. As expected, our selected parcel is near the mean and most probable value of this distribution. In general, parcels at more equatorward latitudes and higher altitudes begin to lose $\mathrm{O}_{3}$ sooner as the sun rises earlier, and complete $\mathrm{O}_{3}$ loss occurs earlier provided they are completely activated and denitrified. The $\mathrm{O}_{3}$ time series from our selected parcel corresponds closely to that of a zonal average of parcels at $75^{\circ} \mathrm{S}\left( \pm 2.5^{\circ}\right)$. All parcels have some latitude excursions, which tend to hasten $\mathrm{O}_{3}$ loss with respect to that at a fixed latitude. For example, we ran earlier calculations fixed at $80^{\circ} \mathrm{S}$ and $\mathrm{O}_{3}$ loss did not begin until about day 240, which did not seem realistic in comparison to observations that represent a potential mix of many actual trajectories. Finally, note that the conclusions discussed above regarding the uncertainty of $\mathrm{O}_{3}$ loss resulting from uncertainty in $\mathrm{Cl}_{2} \mathrm{O}_{2}$ photolysis, the relative comparison between JPL06 and Pope et al., and the contribution of other kinetics uncertainties discussed below do not depend critically on the choice of trajectory. The large majority of Antarctic trajectories would show the same sensitivity.

\subsection{Antarctic comparisons with data}

Comparisons with averaged MLS $\mathrm{O}_{3}$ and $\mathrm{HCl}$ from 20052007 are shown in Fig. 4a and b, respectively. The $\mathrm{O}_{3}$ observations generally follow the JPL06 base case and fall within the $95 \%$ uncertainty limits given by the kinetics uncertainties on the JPL06 rate scenario (assuming an uncertainty factor of 1.5 for the $\mathrm{Cl}_{2} \mathrm{O}_{2}$ cross section). The data are outside the Pope et al. scenario bounds, at least until $\mathrm{O}_{3}$ loss is near complete in October. The day-to-day fluctuations in MLS $\mathrm{O}_{3}$ result from both equivalent latitude excursions of the tra-
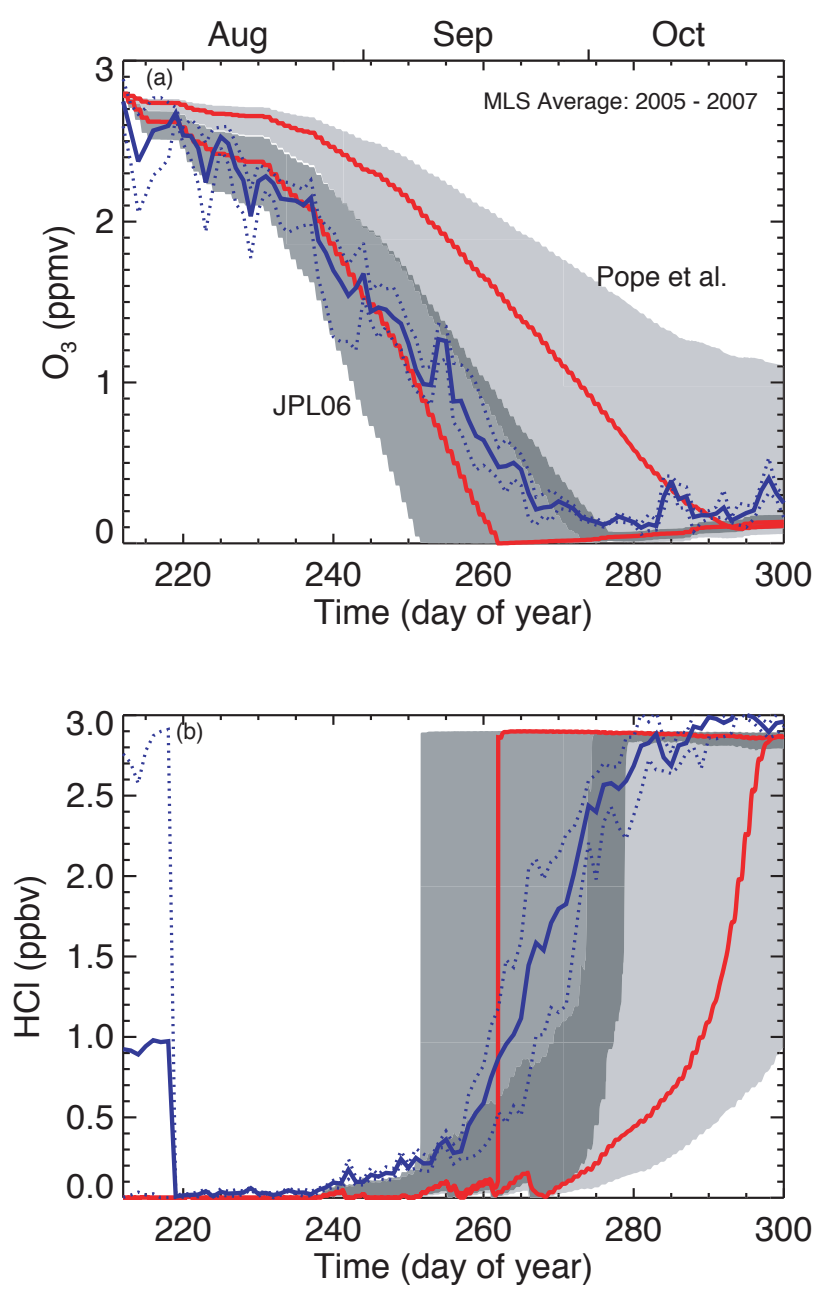

Fig. 4. Comparison of $\mathrm{MLS} \mathrm{O}_{3}$ (a) and $\mathrm{HCl}$ (b) data averaged for 2005-2007 (solid blue lines) with model simulation. Maxima and minima of 3 years of data for each day are shown by dotted lines. Equivalent latitude/potential temperature averaged MLS data are mapped to the equivalent latitude and potential temperature of the model trajectory for each day. Red lines and shading as in Fig. 3a.

jectory and variations in the potential temperature/equivalent latitude averages of the data.

The MLS HCl comparison (Fig. 4b) is consistent with the $\mathrm{O}_{3}$ time series. When $\mathrm{O}_{3}$ mixing ratios fall below about $0.5 \mathrm{ppmv}, \mathrm{HCl}$ increases rapidly, driven by production from reaction of $\mathrm{Cl}$ and $\mathrm{CH}_{4}$ (Douglass et al., 1995; Douglass and Kawa, 1999). The averaged MLS HCl rises more gradually than the unmixed trajectory scenario, but the mixing ratios remain within or near the model error bars given by the JPL06 rate uncertainties through October. Neither MLS dataset is consistent with the Pope et al. (2007) scenario, consistent with the results of Santee et al. (2008).

Comparison of the range of model $\mathrm{O}_{3}$ with sonde data from South Pole (SP) and McMurdo for several years is shown in Fig. 5. In each year at each site, the measured $\mathrm{O}_{3}$ 


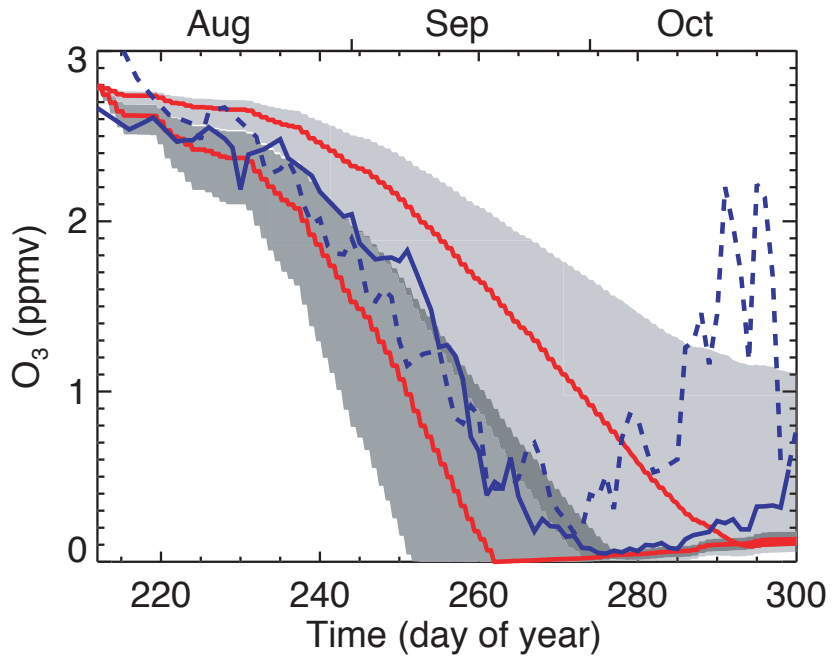

Fig. 5. South Pole $\left(90^{\circ} \mathrm{S}\right.$, solid blue curve) and McMurdo $\left(77.5^{\circ} \mathrm{S}\right.$, dashed blue curve) sonde data at $50 \mathrm{hPa}$ averaged from 1998 to 2007 excluding 2002. Observations have been smoothed with a 3-point running average filter. Red lines and shading as in Fig. 3a.

decreases to near-zero mixing ratios. On most days at SP, the data fall within the 95\% confidence limits on the JPL06 rate scenario and outside the Pope et al. scenario. Note that we might expect $\mathrm{O}_{3}$ loss in the trajectory scenario to lead SP data somewhat since the latitude of the trajectory is equatorward of SP and hence insolation is greater until equinox. The extent to which SP is affected by parcel trajectories from more equatorial latitudes varies, but the data generally show some impact, i.e., the sun does not rise at $50 \mathrm{hPa}$ over SP until about day 246 ( 3 September), when the main $\mathrm{O}_{3}$ decline begins, but some loss has already begun in August in most years. Interannual variation in the loss rate and minimum date is related to meteorological variability, but in all years from 1998 to 2007 (except 2002) $\mathrm{O}_{3}$ at the SP goes to near zero $(<0.1 \mathrm{ppmv})$ within \pm 5 days of day 270 (see Hofmann et al. (1997) and Hofmann et al. (2009) for updates through 2007). Average $\mathrm{O}_{3}$ from McMurdo at $77.5^{\circ} \mathrm{S}$ starts out a bit higher than our trajectory initial condition, but generally falls within the JPL06 limits through September (day 274). McMurdo $\mathrm{O}_{3}$ loss appears to lead SP by several days on average, but the range of the data is relatively large (about $\pm 0.5 \mathrm{ppmv})$.

In October, McMurdo shows the effects of vortex distortion and mixing on local $\mathrm{O}_{3}$ in some years.

\subsection{Arctic comparisons with Match data}

Comparison of the overall Match observed $\mathrm{O}_{3}$ loss rate for the year 2000 with model simulations for a range of $\mathrm{Cl}_{2} \mathrm{O}_{2}$ cross section measurements is shown in Fig. 6. In this case error bars on the model calculation (red curve and bars in Fig. 6) represent the uncertainty in inferring the amount of

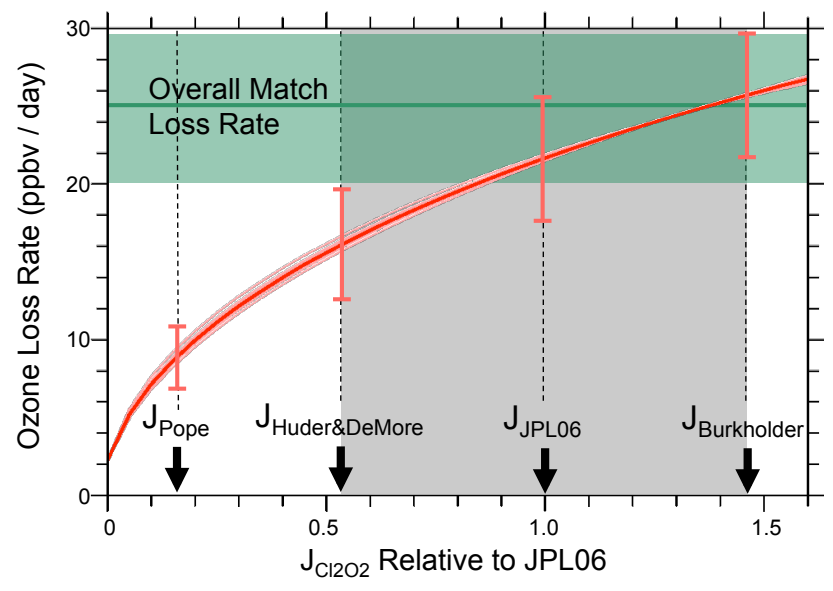

Fig. 6. Comparison of overall Match observed $\mathrm{O}_{3}$ loss rate in early February 2000 (green line; green shading is $1 \sigma$ uncertainty) with model calculations using four different evaluations for $\mathrm{Cl}_{2} \mathrm{O}_{2}$ photolysis cross sections. Red curve is fit to results of chemical calculations along Match trajectories. Model active chlorine abundances are constrained by measurements from SOLVE flight on 2 February 2000. Red error bars are uncertainties in calculated $\mathrm{O}_{3}$ loss rates resulting from propagating the uncertainty in inferring the amount of activated $\mathrm{Cl}$ through the model. Light red lines very close to the center red line reflect uncertainties from propagating uncertainties in the rate constant for the $\mathrm{ClO}$ equilibrium reaction constants (R1) through the model. Gray shaded area denotes range of $J_{\mathrm{Cl}_{2} \mathrm{O}_{2}}$ values, relative to JPL06, that are consistent with $\mathrm{O}_{3}$ observations.

activated $\mathrm{Cl}_{\mathrm{y}}$ for the $\mathrm{O}_{3}$ loss calculation, rather than the kinetics uncertainties. For Match, the best agreement with data occurs for the model based on $\mathrm{Cl}_{2} \mathrm{O}_{2}$ cross sections from Burkholder et al. (1990). The model based on the JPL06 recommendation is within the uncertainty of the data. Model and data errors bars nearly overlap using the Huder and DeMore (1995) cross sections, which are about a factor of 1.5 lower than JPL06, consistent with the constrained uncertainty discussion above. This analysis is consistent with 6 years of Match data, including the Antarctic in 2003 (Frieler et al., 2006). The model with Pope et al. (2007) cross sections is outside observational error limits.

In a complementary approach, the Match $\mathrm{O}_{3}$ loss rates can be "inverted" using the chemistry model to infer the amount of activated $\mathrm{Cl}_{\mathrm{y}}$ required to produce the observed loss rates (Rex et al., 2003). Consistent with the loss rate comparison in Fig. 6, the amount of inferred $\mathrm{Cl}_{\mathrm{y}}$ is within uncertainties on the SOLVE observations (Stimpfle et al., 2004) using Burkholder or JPL06 cross sections (and enhanced Br) (Frieler et al., 2006). The amount of $\mathrm{Cl}_{\mathrm{y}}$ required (3 to $10 \mathrm{ppbv}$ ) to produce observed loss using the Pope et al. cross sections is significantly more than the total chlorine in the stratosphere $(\sim 3.5 \mathrm{ppbv})$. 
Table 1. Sensitivity of the first date of $\mathrm{O}_{3}<0.1 \mathrm{ppmv}$ to changes in individual rate constants of $\pm 1 \sigma$ from JPL06 (except $\mathrm{Cl}_{2} \mathrm{O}_{2}+\mathrm{h} v$ as discussed in text). A positive value of $\Delta \mathrm{t}$ means trajectory $\mathrm{O}_{3}$ for that rate change fell below $0.1 \mathrm{ppmv}$ at a later time than the base case (day 260.88).

\begin{tabular}{llrr}
\hline$\#$ & Reaction & \multicolumn{2}{c}{$\Delta \mathrm{t}$ (days) } \\
\hline & & $+1 \sigma$ & $-1 \sigma$ \\
Reaction (R2) & $\mathrm{Cl}_{2} \mathrm{O}_{2}+\mathrm{h} \nu \rightarrow \mathrm{Cl}+\mathrm{ClOO}$ & -4.95 & 5.88 \\
Reaction (R3b) & $\mathrm{BrO}+\mathrm{ClO} \rightarrow \mathrm{Br}+\mathrm{ClOO}$ & -3.50 & 3.25 \\
Reaction (R5) & $\mathrm{Br}+\mathrm{O}_{3} \rightarrow \mathrm{BrO}+\mathrm{O}_{2}$ & -0.83 & 1.46 \\
Reaction (R3a) & $\mathrm{BrO}+\mathrm{ClO} \rightarrow \mathrm{BrCl}+\mathrm{O}_{2}$ & -0.87 & 0.75 \\
Reaction (R3c) & $\mathrm{BrO}+\mathrm{ClO} \rightarrow \mathrm{Br}+\mathrm{OClO}$ & 0.71 & -0.17 \\
Reaction (R1) & $\mathrm{ClO}+\mathrm{ClO}+\mathrm{M} \rightarrow \mathrm{Cl}_{2} \mathrm{O}_{2}+\mathrm{M}$ & -0.17 & 0.54 \\
& $\mathrm{ClO}+\mathrm{OH} \rightarrow \mathrm{HCl}+\mathrm{O}_{2}$ & 1.42 & 0.04 \\
& $\mathrm{Br}+\mathrm{H}_{2} \mathrm{CO} \rightarrow \mathrm{HBr}+\mathrm{HCO}$ & 0.13 & -0.04 \\
& $\mathrm{HBr}+\mathrm{OH} \rightarrow \mathrm{Br}+\mathrm{H}_{2} \mathrm{O}$ & -0.08 & 0.13 \\
\hline
\end{tabular}

\section{Sensitivity to key reactions and uncertainties}

In addition to the Monte Carlo distribution of rate uncertainties run above, we also ran the Antarctic simulation varying rates one at a time at the $\pm 1 \sigma$ uncertainty limits given in JPL06 (except $J_{\mathrm{Cl}_{2} \mathrm{O}_{2}}$ for which the uncertainty was set at 1.5 as discussed above). The reactions with the largest uncertainty impacts, in terms of date of initial $\mathrm{O}_{3}<0.1 \mathrm{ppmv}$, for the Antarctic scenario are given in Table 1 . The uncertainty in $\mathrm{Cl}_{2} \mathrm{O}_{2}$ photolysis (R2) still has the largest impact on polar $\mathrm{O}_{3}$ loss, but the uncertainty in $\mathrm{ClO}+\mathrm{BrO}(\mathrm{R} 3)$ is close behind. Reaction (R3b) has the largest effect among the possible product yields for (R3) because this channel directly recycles the $\mathrm{Br}$ and $\mathrm{Cl}$ in sunlight, while (R3c) sequesters $\mathrm{Cl}$ in $\mathrm{OClO}$ at low zenith angles (producing the opposite sensitivity). The $\mathrm{BrCl}$ channel (Reaction $\mathrm{R} 3 \mathrm{a}$ ) is a minor pathway $(\sim 8 \%)$ (JPL06). Note that our modeling protocol treats uncertainty in each of these reaction pathways independently, which is probably not the case in the laboratory measurements, where the errors are likely correlated. Regardless of branching ratio, however, this exercise shows that uncertainty in this reaction causes a significant uncertainty in calculating polar $\mathrm{O}_{3}$ loss.

The direct rate of $\mathrm{O}_{3}$ loss with $\mathrm{Br}$ (Reaction R5) has some uncertainty impact, which will, of course, depend on the amount of $\mathrm{Br}_{\mathrm{y}}$ in the vortex. The $\mathrm{Cl}_{2} \mathrm{O}_{2}$ formation and back Reaction (R1), which have substantial uncertainty from lab studies, do not have a large impact on polar $\mathrm{O}_{3}$ loss because thermal dissociation is small compared to photolysis in sunlight, and photolysis (Reaction R2) is generally rate limiting compared to $\mathrm{Cl}_{2} \mathrm{O}_{2}$ formation (Reaction R1) in the $\mathrm{O}_{3}$ loss cycle at high $\mathrm{ClO}$ mixing ratios (i.e., fully activated $\mathrm{Cl}_{\mathrm{y}}$ ). Reaction (R1) is, however, important to the $\mathrm{ClO} / \mathrm{Cl}_{2} \mathrm{O}_{2}$ partitioning and interpretation of ambient $\mathrm{Cl}_{\mathrm{y}}$ measurements (e.g., Stimpfle et al., 2004). Reactions that remove $\mathrm{Cl}$ and $\mathrm{Br}$ from the active catalytic cycle into $\mathrm{HCl}$ and $\mathrm{HBr}$ show some minor impact as does release of $\mathrm{Br}$ from $\mathrm{HBr}+\mathrm{OH}$. Sensitivity to all other reactions is negligible $(<0.1$ days $)$ in this scenario.

The Arctic Match $\mathrm{O}_{3}$ loss uncertainty is also dominated by the top two reaction sensitivities as in Table 1, with Reaction (R1) in a distant third place. These findings are similar to those of Fish and Burton (1997) in the Arctic using JPL94 kinetic rates, although Fish and Burton found that Reaction (R3b) contributed a slightly larger uncertainty than Reaction (R2). In lieu of a recommendation from JPL94, Fish and Burton estimated $\sigma\left(J_{\mathrm{Cl}_{2} \mathrm{O}_{2}}\right)$ at a factor of 2, which they considered possibly overestimated in light of atmospheric $\mathrm{ClO}$ data. The nominal recommended cross sections in JPL06 are the same as those in JPL94, and, while the mean rates for Reaction (R3) have changed slightly, the uncertainty bounds have not. The different ranking of reaction uncertainties from Fish and Burton probably arises from the specifics of the trajectories used and the $\mathrm{Cl}_{\mathrm{y}}$ and $\mathrm{Br}_{\mathrm{y}}$ abundances.

\section{Summary discussion}

Quantitative evaluation of chemical uncertainty underlying stratospheric assessment models shows that known uncertainties in kinetic reaction rate parameters from laboratory measurements produce large uncertainty in polar $\mathrm{O}_{3}$ loss calculated in simple, representative models. For both Antarctic and Arctic $\mathrm{O}_{3}$ loss, the Monte Carlo uncertainty distribution is dominated by the recommended JPL06 uncertainty in photolysis cross sections for $\mathrm{Cl}_{2} \mathrm{O}_{2}$ at atmospherically relevant wavelengths. This uncertainty is large enough to include the recent cross section measurements of Pope et al. (2007), which imply greatly reduced polar $\mathrm{O}_{3}$ loss rates in a standard model mechanism. New laboratory measurements are required to better interpret these and earlier results and diminish the error bounds. This finding is consistent with previous work, and several new lab studies are in progress (SPARC, 2009).

Evidence from atmospheric measurements, however, suggests that the $\mathrm{Cl}_{2} \mathrm{O}_{2}$ photolysis rate can be constrained more tightly than the lab data indicate. When the photolysis rate uncertainty in the Monte Carlo simulations is constrained by atmospheric observations, the impact of varying $\mathrm{Cl}_{2} \mathrm{O}_{2}$ cross sections between JPL06 and Pope et al. (2007) is distinct at the 95\% confidence level for spring/winter Antarctic $\mathrm{O}_{3}$ loss. In this case, comparison to observations shows the ozonesonde, MLS, and Match data are consistent with JPL06 kinetic rates within model uncertainty. This lends confidence that the chemical mechanism and JPL06 rates in the models are representative and reasonably accurate. Note that if $J_{\mathrm{Cl}_{2} \mathrm{O}_{2}}$ is close to that produced from Pope et al. (2007), a large fraction of the observed $\mathrm{O}_{3}$ loss cannot be explained by the standard chemistry mechanism. Efforts to simultaneously explain all the relevant theoretical, laboratory, and atmospheric data by identifying missing processes or using 
an alternate chemical mechanism have yet to yield a solution (SPARC, 2009).

Sensitivity tests have also shown that uncertainty in the rate and branching ratio for $\mathrm{BrO}+\mathrm{ClO}$ has a significant impact on uncertainty in polar $\mathrm{O}_{3}$ loss calculations in both hemispheres. This finding is consistent with previous work based on earlier rate compilations at midlatitudes and in the Arctic, and leads us to a recommendation for further laboratory work on this reaction as well. The importance of this reaction is closely tied to the amount of bromine in the lower stratosphere, which also has significant uncertainty based on current measurements. Uncertainty in the key chemical reaction kinetics must be reduced in order to confidently assess the impact of changes in bromine and other trace gases on future projections of polar $\mathrm{O}_{3}$ loss and recovery.

Acknowledgements. We would like to acknowledge support from the Atmospheric Chemistry Modeling and Analysis and the Modeling, Analysis, and Prediction Programs at NASA. Work at the Jet Propulsion Laboratory, California Institute of Technology, was done under contract with the National Aeronautics and Space Administration. Work at AWI was supported by the EC DG Research through the RECONCILE project. The McMurdo data used in this publication were obtained as part of the Network for the Detection of Atmospheric Composition Change (NDACC) and are publicly available (see http://www.ndacc.org).

Finally, we would like to acknowledge the contributions of our friend and colleague, the late Dave Hofmann, to this paper and to the understanding of stratospheric aerosol and ozone more generally. The long-term data records and analysis that he produced and supported are invaluable. Dave was a great contributor over a long and illustrious career, and he will be missed.

Edited by: P. Jöckel

\section{References}

Avallone, L. M. and Toohey, D. W.: Tests of halogen photochemistry using in situ measurements of $\mathrm{ClO}$ and $\mathrm{BrO}$, J. Geophys. Res., 106(10), 10411-10421, 2001.

Burkholder, J. B., Orlando, J. J., and Howard, C. J.: Ultravioletabsorption cross-sections of $\mathrm{Cl}_{2} \mathrm{O}_{2}$ between 210 and $410 \mathrm{~nm}, \mathrm{~J}$. Phys. Chem., 94, 687-695, 1990.

Chen, H.-Y., Lien, C.-Y., Lin, W.-Y., Lee, Y. T., and Lin, J. J.: UV absorption cross sections of $\mathrm{ClOOCl}$ are consistent with ozone degradation models, Science, 324, 781-784, 2009.

Considine, D.B., Stolarski, R. S., Hollandsworth, S. M., Jackman, C. H., and Fleming, E. L.: A Monte Carlo uncertainty analysis of ozone trend predictions in a two-dimensional model, J. Geophys. Res., 104, 1749-1765, 1999.

DeMore, W. B., Sander, S. P., Golden, D. M., et al.: Chemical Kinetics and Photochemical Data for Use in Stratospheric Modeling, Evaluation Number 11, JPL Publication 94-26, Jet Propulsion Laboratory, Pasadena, CA, USA, 1994.

DeMore, W. B., Sander, S. P., Golden, D. M., et al.: Chemical Kinetics and Photochemical Data for Use in Stratospheric Modeling, Evaluation Number 12, JPL Publication 97-4, Jet Propulsion Laboratory, Pasadena, CA, USA, 1997.
Douglass, A. R., Schoeberl, M. R., Stolarski, R. S., Waters, J. W., Russell, J. M., Roche, A. E., and Massie, S. T.: Interhemispheric differences in springtime production of $\mathrm{HCl}$ and $\mathrm{ClONO} 2$ in the polar vortices, J. Geophys. Res., 100, 13967-13978, 1995.

Douglass, A. R. and Kawa, S. R.: Contrast between 1992 and 1997 high latitude Spring Halogen Occultation Experiment observations of lower stratospheric HCl, J. Geophys. Res., 104, 18739 18754, 1999.

Fish, D. J. and Burton, M. R.: The effect of uncertainties in kinetic and photochemical data on model predictions of stratospheric ozone depletion, J. Geophys. Res., 102, 25537-25542, 1997.

Frieler, K., Rex, M., Salawitch, R. J., Canty, T., Streibel, M., Stimpfle, R. M., Pfeilsticker, K., Dorf, M., Weisenstein, D. K., and Godin-Beekmann, S.: Toward a better quantitative understanding of polar stratospheric ozone loss, Geophys. Res. Lett., 33, L10812, doi:10.1029/2005GL025466, 2006.

Hofmann, D. J., Oltmans, S. J., Harris, J. M., Johnson, B. J., and Lathrop, J. A.: Ten years of ozonesonde measurements at the South Pole: Implications for recovery of springtime Antarctic ozone, J. Geophys. Res., 102, 8931-8943, 1997.

Hofmann, D. J., Johnson, B. J. and Oltmans, S. J.: Twenty-two years of ozonesonde measurements at the South Pole, Proceedings of the Quadrennial Ozone Symposium, Tromso, Norway, 2008, J. Remote Sens., 30, 3995-4008, 2009.

Hoppel, K., Bevilacqua, R., Canty, T., Salawitch, R. J., and Santee, M. L.: A measurement/model comparison of ozone photochemical loss in the Antarctic ozone hole using Polar Ozone and Aerosol Measurement observations and the Match technique, J. Geophys. Res., 110, D19304, doi:10.1029/2004JD005651, 2005.

Huder, K. J. and DeMore, W. B.: Absorption cross sections of the ClO dimer, J. Phys. Chem., 99, 3905-3908, 1995.

Kawa, S. R., Newman, P. A., Lait, L. R., Schoeberl, M. R., Stimpfle, R. M., Kohn, D. W., Webster, C. R., May, R. D., Baumgardner, D., Dye, J. E., Wilson, J. C., Chan, K. R., and Loewenstein, M.: Activation of chlorine in sulfate aerosol as inferred from aircraft observations, J. Geophys. Res., 102, 3921-3933, 1997.

Nardi, B., Bellon, W., Oolman, L. D., and Deshler, T.: Spring 1996 and 1997 ozonesonde measurements over McMurdo Station, Antarctica, Geophys. Res. Lett., 26, 723-726, 1999.

Newman, P. A., Harris, N. R. P., Adriani A., et al.: An overview of the SOLVE/THESEO 2000 campaign, J. Geophys. Res., 107(D20), 8259, doi:10.1029/2001JD001303, 2002.

Newman, P. A., Nash, E. R., Kawa, S. R., Montzka, S. A., and Schauffler, S. M.: When will the Antarctic ozone hole recover?, Geophys. Res. Lett., 33, L12814, doi:10.1029/2005GL025232, 2006.

Pierson, J. M., Kawa, S. R., Salawitch, R. J., Hanisco, T. F., Lanzendorf, E. J., Perkins, K. K., and Gao, R. S.: The influence of airmass histories on radical species during POLARIS, J. Geophys. Res., 105, 15185-15199, 2000.

Pope, F. D., Hansen, J. C., Bayes, K. D., Friedl, R. R., and Sander, S. P.: J. Phys. Chem., 111, 4322-4332, 2007.

Rex, M., von der Gathen, P., Harris, N. R. P., Lucic, D., Knudsen, B. M., Braathen, G.O., Reid, S. J., De Backer, H., Claude, H., Fabian, R., Fast, H., Gil, M., Kyro, E., Mikkelsen, I. S., Rummukainen, M., Smit, H. G., Stahelin, J., Varotsos, C., and Zaitcev, I.: In situ measurements of stratospheric ozone depletion rates in the Arctic winter 1991/1992: A Lagrangian approach, J. Geophys. Res., 103, 5843-5853, 1998. 
Rex M., Salawitch, R. J., Harris, N. R. P., von der Gathen, P., Braathen, G. O., Schulz, A., Deckelmann, H., Chipperfield, M., Sinnhuber, B. M., Reimer, E., Alfier, R., Bevilacqua, R., Hoppel, K., Fromm, M., Lumpe, J., Kullmann, H., Kleinbohl, A., Bremer, H., von Konig, M., Kunzi, K., Toohey, D., et al.: Chemical depletion of Arctic ozone in winter 1999/2000, J. Geophys. Res., 107 (D20), 8276, doi:10.1029/2001JD000533, 2002.

Rex, M., Salawitch, R. J., Santee, M. L., Waters, J. W., Hoppel, K., and Bevilacqua, R.: On the unexplained stratospheric ozone losses during cold Arctic Januaries, Geophys. Res. Lett., 30(1), 1008, doi:10.1029/2002GL016008, 2003.

Salawitch, R. J., Weisenstein, D. K., Kovalenko, L. J., Sioris, C. E., Wennberg, P. O., Chance, K., Ko, M. K. W. and McLinden, C. A.: Sensitivity of ozone to bromine in the lower stratosphere, Geophys. Res. Lett., 32, L05811, doi:10.1029/2004GL021504, 2005.

Sander, S. P., Friedl, R. R., Golden, D. M., Kurylo, M. J., Huie, R. E., Orkin, V. L., Moortgat, G. K., Ravishankara, A. R., Kolb, C. E., Molina, M. J., and Finlayson-Pitts, B. J.: Chemical Kinetics and Photochemical Data for Use in Atmospheric Studies, Evaluation Number 14, JPL Publication 02-25, Jet Propulsion Laboratory, Pasadena, CA, USA, 2003.

Sander, S. P., Friedl, R. R., Golden, D. M., Kurylo, M. J., Moortgat, G. K., Keller-Rudek, H., Wine, P. H., Ravishankara, A. R., Kolb, C. E., Molina, M. J., Finlayson-Pitts, B. J., Huie, R. E., and Orkin, V. L.: Chemical Kinetics and Photochemical Data for Use in Atmospheric Studies, Evaluation Number 15, JPL Publication 06-02, Jet Propulsion Laboratory, Pasadena, CA, USA, 2006.

Santee, M. L., MacKenzie, I. A., Manney, G. L., Chipperfield, M. P., Bernath, P. F., Walker, K. A., Boone, C. D., Froidevaux, L., Livesey, N. J., and Waters, J. W.: A study of stratospheric chlorine partitioning based on new satellite measurements and modeling, JGR 113, D12307, doi:10.1029/2007JD009057, 2008.

Schofield R., Frieler, K., Wohltmann, I., Rex, M., von Hobe, M., Stroh, F., Koch, G., Peter, T., Canty, T., Salawitch, R. J., and Volk, C. M.: Polar stratospheric chlorine kinetics from a selfmatch flight during SOLVE-II/EUPLEX, Geophys. Res. Lett., 35, L01807, doi:10.1029/2007GL031740, 2008.
Stratospheric Processes and Their Role in Climate: The Role of Halogen Chemistry in Polar Stratospheric Ozone Depletion: Report from the June 2008 Cambridge, UK Workshop for an Initiative under the Stratospheric Processes and Their Role in Climate (SPARC) Project of the World Climate Research Programme, onine available at http://www.atmosp.physics.utoronto. ca/SPARC/HalogenChem_Final_20090213.pdf, 2009.

Stimpfle, R. M., Wilmouth, D. M., Salawitch, R. J., and Anderson, J. G.: First measurements of $\mathrm{ClOOCl}$ in the stratosphere: The coupling of $\mathrm{ClOOCl}$ and $\mathrm{ClO}$ in the Arctic polar vortex, J. Geophys. Res., 109, D03301, doi:10.1029/2003JD003811, 2004.

Stolarski, R. S., Butler, D. M., and Rundel, R. D.: Uncertainty propagation in a stratospheric model 2. Monte Carlo analysis of imprecisions due to reaction rates, J. Geophys. Res., 83, 30743078, 1978.

Stolarski, R. S. and Douglass, A. R.: Sensitivity of an atmospheric photochemistry model to chlorine perturbations including consideration of uncertainty propagation, J. Geophys. Res., 91, 7853-7864, 1986.

von Hobe, M., Salawitch, R. J., Canty, T., Keller-Rudek, H., Moortgat, G. K., Grooß, J.-U., Müller, R., and Stroh, F.: Understanding the kinetics of the $\mathrm{ClO}$ dimer cycle, Atmos. Chem. Phys., 7, 3055-3069, 2007, http://www.atmos-chemphys.net/7/3055/2007/.

von Hobe, M., Stroh, F., Beckers, H., Benter, T., and Willner, H.: The UV/Vis absorption spectrum of matrix-isolated dichlorine peroxide, $\mathrm{ClOOCl}$, Phys. Chem. Chem. Phys., 11, 1571-1580, 2009.

World Meteorological Organization (WMO), Scientific assessment of ozone depletion: 2006, WMO Rep. 50, Global Ozone Res. and Monit. Proj., Geneva, Switzerland, 2007. 